\title{
Urban Ecosystem Health Assessment of Foshan city based on Entropy and Grey Prediction Model
}

\author{
Liu Hui \\ School of Geography and Tourism, Guangdong University of Finance and Economics, Guangzhou, China
}

\begin{abstract}
According to the connotation of urban ecosystem health and the ecosystem situation in Foshan, the health assessment index system was constructed which including five factors of vigor, organization, resilience, ecosystem service, population health and the assessment standard was also determined. The index weight was determined by entropy value method. Fuzzy mathematical evaluation method was applied to Foshan urban ecosystem health assessment from 2003 to 2012. Grey predicting model GM $(1,1)$ was established to analyze dynamic of ecosystem health in future. The results showed that urban ecosystem health developed from sick status to unhealthy status and healthy status in Foshan during 2003-2012. Vigor and organization were two factors advantageous to urban ecosystem health. Ecosystem service had been improved a lot. Resilience and population health were the two main stressful factors of urban ecosystem health. On the whole, Foshan urban ecosystem health showed an improving trend year by year. The status of ecosystem health had much to be improved through proper measures to alleviate or eliminate the stress factors. The GM $(1,1)$ model had good performance on model fitting and forecasting. It showed the city would maintain a good development in the next five years.
\end{abstract}

\section{Introduction}

Urbanization significantly influences the functioning of local and global earth ecosystems and the services they provide to humans and other life on earth [1].Urban development disturbs the hydrological system, changed the energy flow and nutrient cycling. Because of industry development and excessive concentration of population, city needs to consume large amounts of natural resources and release large amounts of waste into the environment. It can cause both global and regional excessive consumption of natural resources and bring many urban problems such as traffic congestion, urban unemployment rate, housing shortage, environmental pollution, ecological deterioration, etc [2]. Since humans depend on earth ecosystems for food, water, and other important products and services, changes in ecological conditions that result from human actions in urban areas ultimately affect human health and well-being [1]. Therefore, it's necessary to keep a harmony and healthy urban ecosystem for a sustainable society. From the ecosystem health perspective, the maintenance of the health of ecosystems, so that they maintain their full potential to sustain life itself, is the primary focus [3].

The key of urban ecosystem health research is to set desired criteria for selecting suitable indicators [4]. Considering the states and physical driving mechanisms, the indicators tend to be easy to understand and regulate, which is convenient and beneficial for the practical urban ecological management [5]. Liu et al. chose four major factors, including vigor, organization, resilience and ecosystem service to construct a novel enery-based urban ecosystem health index in assessment of Baotou city, China [4]. Guo et al. Chose five major factors, adding population health status except the four above in assessment of Chongqing city [6]. Following the principle of ecosystem health assessment, five main factors were chosen in this paper. The objects of this paper were to assess the urban ecosystem health in Foshan city based on its natural, social and economic development in the late 10 years and to predict its health state in the future.

\section{Methods}

Assessment index system must be designed to reflect the urban ecosystem health status according to their characteristics of abstracting information from a complicated system to reduce the complexity and to connect the theoretical ecological background with related political practical requirements [5]. The urban ecosystem is a social-economic-natural complex. It means the factors selected should be integrated with all the three aspects. We chose five factors, vigor, organization structure, resilience, ecosystem service and population health to construct the assessment index system which had been widely used in urban ecosystem health assessment [7, 8]. 27 specific indicators were selected according to the ecosystem situation in Foshan (Table 1 ). The standard of each indicator was divided into five grades, ill, unhealthy, sub-healthy, healthy, healthier according to Guo's research [7]. The best grade was defined based on the suggested value from related literature or national standards or planning of eco-city. The ill grade is based on the worst value observable in a Chinese city for each standard. And then, based on the two established anchor points, the remaining three middle grades are determined through interpolation $[5,7]$. The result of standard was showed in table 1 .

The entropy model used to calculate each index makes it more objective to screen important indicator and compression evaluation system on the maximum based on the evaluation results without losing accuracy [9]. The results of weights of indices were showed in table 1 .

The results were based on fuzzy synthetic assessment and grey system theory. Grey system theory was an interdisciplinary scientific area that was first introduced in early 1980s by Deng [10]. Since then, the theory has become quite popular with its ability to deal with the systems that have partially unknown parameters. As a 
superiority to conventional statistical models, grey models require only a limited amount of data to estimate

the behaviour of unknown systems [11].

Table 1. The urban ecosystem health ssessment indices, standards and weights of Foshan city.

\begin{tabular}{|c|c|c|c|c|c|c|c|}
\hline $\begin{array}{l}\text { Assessment } \\
\text { factors } \\
\text { (weights) }\end{array}$ & Assessment indicators (unit) & Sick & Unhealthy & Sub- healthy & healthy & Healthier & $\begin{array}{l}\text { Indicat } \\
\text { or } \\
\text { weights }\end{array}$ \\
\hline Vigor & Per capita GDP ( million) & 3.00 & 5.00 & 10.00 & 15.00 & 20.00 & 0.1663 \\
\hline \multirow[t]{5}{*}{$(0.2073)$} & Annual GDP growth rate (\%) & 6.00 & 8.00 & 10.00 & 12.00 & 14.00 & 0.1063 \\
\hline & $\begin{array}{l}\text { Energy consumption per unit of GDP ( tce . } \\
\text { million }^{-1} \text { ) }\end{array}$ & 2.00 & 1.50 & 1.00 & 0.70 & 0.50 & 0.2524 \\
\hline & $\begin{array}{l}\text { Per capita disposable income of urban } \\
\text { residents ( } 10 \text { thousand ) }\end{array}$ & 0.40 & 0.80 & 1.20 & 1.60 & 2.00 & 0.2130 \\
\hline & $\begin{array}{l}\text { Amount of foreign capital actually used } \\
\text { (USD } 100 \text { million) }\end{array}$ & 10.00 & 25.00 & 50.00 & 75.00 & 90.00 & 0.1394 \\
\hline & Natural population growth rate(\%) & 13.00 & 11.00 & 9.00 & 7.00 & 5.00 & 0.1227 \\
\hline Organization & $\begin{array}{l}\text { Population density in central area } \\
\text { (cap . } \mathrm{km}^{-2} \text { ) }\end{array}$ & 4000 & 3000 & 2000 & 1000 & 900 & 0.2058 \\
\hline \multirow[t]{4}{*}{$(0.1705)$} & Proportion of tertiary industry in GDP (\%) & 30.00 & 40.00 & 50.00 & 60.00 & 80.00 & 0.2195 \\
\hline & $\begin{array}{l}\text { Proportion of tertiary industry practitioners } \\
(\%)\end{array}$ & 20.00 & 30.00 & 45.00 & 60.00 & 70.00 & 0.1621 \\
\hline & Urban registered unemployment rate (\%) & 4.80 & 4.20 & 3.30 & 2.10 & 1.20 & 0.2147 \\
\hline & Urban green coverage of built-up areas (\%) & 20.00 & 25.00 & 30.00 & 40.00 & 50.00 & 0.1979 \\
\hline Resilience & $\begin{array}{l}\text { Industrial waste water discharge compliance } \\
\text { rate }(\%)\end{array}$ & 70.00 & 75.00 & 85.00 & 95.00 & 100.00 & 0.0944 \\
\hline \multirow[t]{5}{*}{$(0.1821)$} & Urban sewage treatment rate $(\%)$ & 30.00 & 50.00 & 70.00 & 95.00 & 100.00 & 0.1774 \\
\hline & $\begin{array}{l}\text { Hazard-free treatment rate of domestic } \\
\text { garbage }(\%)\end{array}$ & 60.00 & 70.00 & 80.00 & 90.00 & 100.00 & 0.1301 \\
\hline & $\begin{array}{l}\text { Industrial solid waste comprehensive } \\
\text { utilization rate(\%) }\end{array}$ & 60.00 & 70.00 & 80.00 & 90.00 & 100.00 & 0.1560 \\
\hline & $\begin{array}{l}\text { Society fixed asset investment growth } \\
\text { rate(\%) }\end{array}$ & 10.00 & 20.00 & 30.00 & 40.00 & 50.00 & 0.2462 \\
\hline & $\begin{array}{l}\text { Environmental protection investment share } \\
\text { of GDP }(\%)\end{array}$ & 1.00 & 1.50 & 2.00 & 3.00 & 5.00 & 0.1959 \\
\hline $\begin{array}{l}\text { Ecosystem } \\
\text { service }\end{array}$ & Per capita residential housing areas $\left(\mathrm{m}^{2}\right)$ & 15.00 & 20.00 & 30.00 & 40.00 & 45.00 & 0.1858 \\
\hline \multirow[t]{4}{*}{$(0.2181)$} & Per capita road area $\left(\mathrm{m}^{2}\right)$ & 6.00 & 10.00 & 15.00 & 20.00 & 28.00 & 0.2882 \\
\hline & Per capita urban public green area $\left(\mathrm{m}^{2}\right)$ & 4.00 & 8.00 & 12.00 & 16.00 & 20.00 & 0.3086 \\
\hline & Excellent rate of ambient air quality（\%） & 20.00 & 40.00 & 60.00 & 80.00 & 100.00 & 0.0673 \\
\hline & Cell phone numbers of 100 families & 60 & 100 & 150 & 200 & 300 & 0.1502 \\
\hline $\begin{array}{l}\text { Population } \\
\text { health status }\end{array}$ & Engel coefficient & 50.00 & 45.00 & 35.00 & 30.00 & 25.00 & 0.1230 \\
\hline \multirow[t]{4}{*}{$(0.2220)$} & $\begin{array}{l}\text { Number of hospital beds among ten } \\
\text { thousand people }\end{array}$ & 20.00 & 30.00 & 40.00 & 50.00 & 60.00 & 0.1484 \\
\hline & $\begin{array}{l}\text { Number of doctors among ten thousand } \\
\text { people }\end{array}$ & 20.00 & 30.00 & 40.00 & 50.00 & 60.00 & 0.4437 \\
\hline & $\begin{array}{l}\text { Number of college students among ten } \\
\text { thousand people }\end{array}$ & 50 & 150 & 300 & 450 & 600 & 0.0838 \\
\hline & $\begin{array}{l}\text { Number of buses among ten thousand } \\
\text { people }\end{array}$ & 5.00 & 10.00 & 20.00 & 30.00 & 40.00 & 0.2012 \\
\hline
\end{tabular}




\section{Results and Discussion}

\subsection{Comprehensive assessment of urban ecosystem health}

The main aspects of urban ecosystem health assessment such as the economic, ecological and social performance have all been considered as influential factors for choosing the cases, taking into account the sufficiency and availability of data [5]. In this article, the urban ecosystem health evaluation index system and evaluation standard were built according to the actual circumstance of Foshan. It's more objective to use the entropy method to determine the index weight. The evaluation results could show a true reflection of change of Foshan urban ecosystem health.

The membership degree value of sick state of health assessment showed a significant decline during the ten years ( from 0.3283 in 2003 to 0.1050 in 2012) (Fig. 1A).The unhealthy value was rising while sub-healthy value was declining. The sum of healthy and healthier membership degree value showed a rising trend from 0.3210 in 2003 to 0.4656 in 2012 (Fig. 1A). Results showed that the government made the original pathological factors from sick into unhealthy and healthy state in the process of urban development in Foshan city. According to the biggest membership degree principle, the urban ecosystem health state was in turn: sick, sick, sick, sick, unhealthy, unhealthy, healthy, healthy, healthy, healthy during 2003-2012 (Fig. 1A).

\subsection{Analysis of five assessment factors of urban ecosystem health}

Vigor is the capacity of the system to sustain itself (transmit/reproduce) so that its potential for life in both nature and culture is undiminished [12]. It showed an increasing trend in Foshan urban ecosystem health. It was in a sub-healthy state in 2003, sick in 2004, healthier from 2005 to 2012 based on the principle of maximum membership degree (Fig. 1B). It contributed a lot to Foshan urban ecosystem health. The sum of healthy and healthier membership degree value of vigor increased from 0.3795 to 0.6943 during 2003- 2010 with a slight decline after that (Fig. 1B). The increase of vigor was mainly due to the rapid economic development which was including the increase of per capita GDP , urban per capita disposable income and the actual use of foreign capital, and also the decline of energy consumption per unit GDP. The continuous decline in energy consumption per unit GDP meant effective resource utilization. Although the natural population growth rate fluctuated, but it was lower than the control targets of Foshan city development planning.

The state of organization was healthy during 20032012 except 2003 and 2008 in unhealthy and pathological conditions (Fig. 1C). The result showed that organization also contributed a lot to Foshan urban ecosystem health. The main reason was that Foshan city was in a period of rapid economic development with a main development of industry. The tertiary industry was not high with $30 \%$ to $40 \%$ proportion of the total city GDP. It promoted the social and economic development and stability with a low urban unemployment rate at about $2 \%$ during the 10 years. The sum of healthy and healthier membership degree value of organization increased from 2003 to 2007 and declined in 2008 with little change from 2009 to 2012 (Fig. 1C). The decline of greenbelt area and the tertiary industry were the main reasons causing the ill state of organization. Green coverage rate varied little during 2003-2012 and should be improved a lot.

Resilience reflects the ability of self-organizing of urban ecosystem and human waste disposal capacity. Unlike vigor, it's difficult to measure directly. Five major indicators were chosen to stand for resilience. It showed resilience fluctuated much in 10 years with a healthy state in 2003, sub-healthy or pathological state in 2004-2009 and restored to healthy or healthier state after that (Fig. 1D). The rate of city sewage treatment was a stress element of resilience. Hazard-free treatment rate of domestic garbage was the main stress element for the first three years and had kept healthy since 2006. Industrial solid waste comprehensive utilization was in a healthy state all the time. There was a decrease in the growth rate of investment in fixed assets or remain low and environmental protection investment as a share of GDP also had a declining trend. These two elements had been the main factors influencing the health level of resilience.

The ecosystem services were in sub-healthy state in 2003, 2004, 2006 and healthy in 2005, 2007-2012 (Fig. $1 \mathrm{E})$. The sum of membership degree of healthy and healthier showed a rising trend from 2003 to 2012 (Fig. $1 \mathrm{E}$ ) because of the rise of the per capita housing area and mobile phone number. The sum of sick and unhealthy levels changed little (Fig. 1E) . The main stressful factor to ecosystem services was per capita road area. Because of the large population in city and the influx of foreign population, it caused a lot of pressure to the city resources which gave the public facilities such as road area per capita, public green space, etc. no significant increase.

As humans are integral to the composition of ecosystems, it is also necessary to approach the question of evaluating the health of ecosystems from human health [3]. People health elements of urban ecosystem health status had been sick or unhealthy for a long time until it got improved to a sub-healthy state in 2012 (Fig. 1F). The main stressors to population health were ten thousand people with medical practitioners, the number of ten thousand people with college students and ten thousand people with low number of bus. It meant that Foshan city was facing shortages of education resources, limited medical resources and public transport resources. It also showed that people health was the weakest link of five factors and the most stressful factor of the whole urban ecosystem health. It seemed improved a little based on the increasing sum of sick and unhealthy membership degree after 2008. 

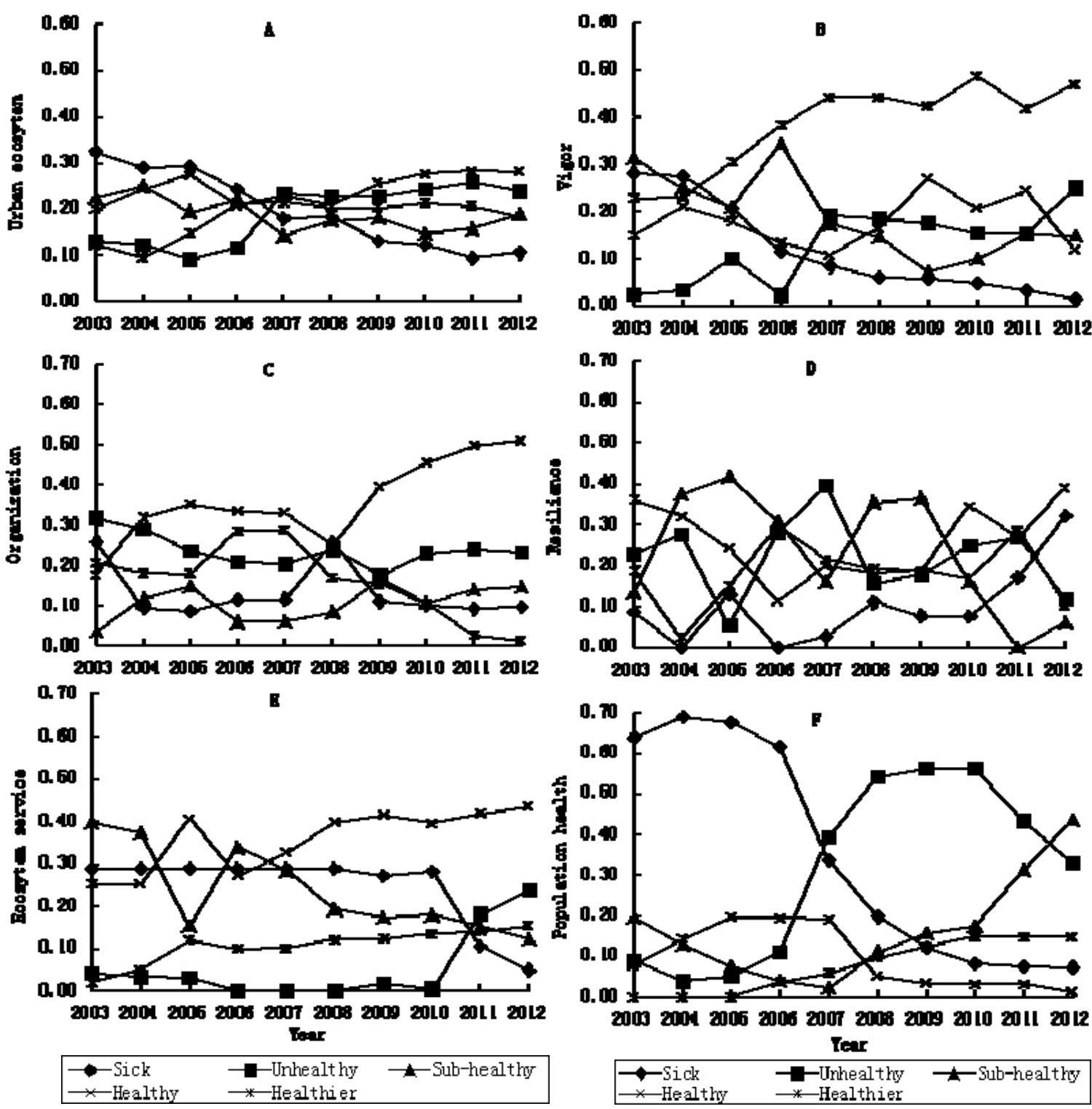

Figure 1.The results of urban ecosystem health assessment in Foshan city during 2003-2012

\subsection{The predicted results based on $\operatorname{GM}(1,1)$ model}

GM $(1,1)$ model was designed based on the sum of healthy and healthier membership degree value. The predicted result of urban ecosystem health assessment for the next 5 years according to formula (11) was showed in figure 2. Prediction model GM $(1,1)$ was based on gray accumulation generation sequence. It showed strong regularity in the forecast results and suitable for the trend prediction of a short term. It showed a math between the ecosystem health assessment value curve and the GM (1, 1) model prediction curve (Fig.2). Predicted ecosystem health showed a steadily rising trend in 2013-2017 (Fig.2).. 


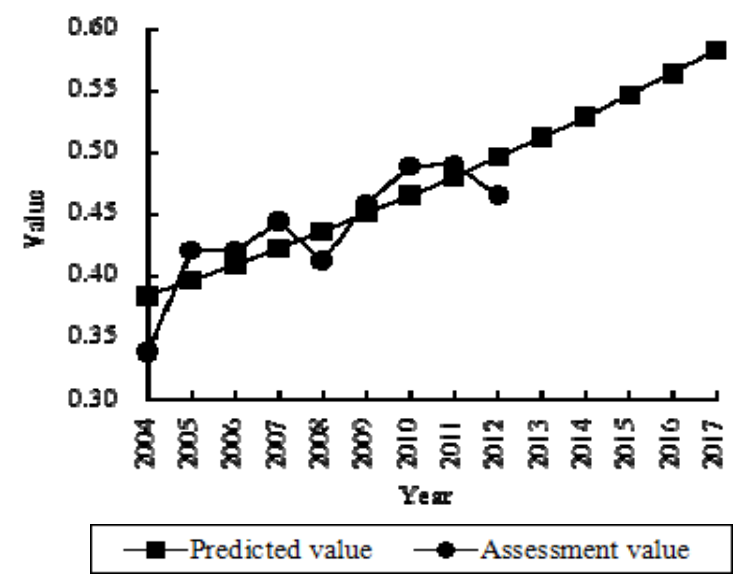

Figure 2. Prediction of urban ecosystem health assessment in 2013-2017.

\section{Conclusions}

Five factors (vigor, organization, resilience, ecosystem service and population health status ) and 27 indicators were chosen to construct the assessment index system of urban ecosystem health according to the actual situation of Foshan city in this article. The urban ecosystem health was evaluated based on the entropy weight method and fuzzy mathematical evaluation method. The results showed that Foshan urban ecosystem health was in pathological level during 2003-2006, unhealthy during 2007-2008 and healthy during 2009-2012. It showed an improved development of ecosystem health in the late 10 years in Foshan city. Of the five evaluation factors, vigor and organization were advantageous elements, ecosystem service was moderate, resilience and population health status were restricting elements in this city. According to the results, Foshan government should focus on improve the resilience, population health and ecosystem service in future development. The predicted results based on grey predicting model GM $(1,1)$ showed Foshan urban ecosystem health would maintain a good trend in the next five years.

Healthy ecosystems are an essential condition of healthy people, healthy communities, and sustainable livelihoods [3]. However, ecosystem health research is still in the phase of theoretical exploration and test accumulation. It's difficult to know if it's the symptoms of interference or symptoms of illness or a stage of succession process since ecosystem is complex, uncertain and always in a dynamic process of succession. Therefore, it's necessary to define the ecosystem health accurately, determine the health standards and background value. Appropriate health evaluation index should be selected based on the ecological, social, economic and human factors. It's necessary to determine the most stressful dangerous components and serious problems and also the key factors that cause these problems. Then the comprehensive evaluation of ecosystem health would be obtained.

\section{References}

[1] Marina, A. The effects of urban patterns on ecosystem function. International Regional Science Review 2005, 28, 168-192.

[2] Meirong, S.; Yan, Z.; Gengyuan, L.; Linyu, X.; Lixiao, Z.; Zhifeng. Y. Urban ecosystem health assessment: perspectives and Chinese practice. International Journal of Environmental Research and Public Health 2013, 10, 5874-5885.

[3] Rapport, D.J. Sustainability science: an ecohealth perspective. Sustainability Science 2007, 2. 77-84.

[4] Liu, G.Y. ; Yang , Z.F.; Chen, B.; Zhang, Y.; Zhang, L.X.; Zhao, Y.W.; Jiang, M.M. Emergy-based urban ecosystem health assessment: A case study of Baotou, China. Communications in Nonlinear Science and Numerical Simulation 2009, 14, 972-981.

[5] Meirong, S.; Fath, B.D.; Yang, Z.F. Urban ecosystem health assessment: A review. Science of the Total Environment 2010, 408, 2425-2434.

[6] Ruili, G.; Zheng Q.; Liu, J.; Li, M. Ecosystem health assessment of Chongqing City based on entropy and $\operatorname{GM}(1,1)$ model. China EnvironmentaI Science 2012, 32, 1148 - 1152.

[7] Ruili, G.; Yang, J.R.; Mao, X.Q. Primary studies on urban ecosystem health assessment. China Environmental Science, 2002, 22, 525-529.

[8] Meirong, S.; Yang, Z.F.; Wang, H.R.; Yang, X.H. A kind of method and its application for urban ecosystem health assessment. Acts Scientiae Circumstantiae 2006, 26, 2072-2080.

[9] Xianqi, Z.; Chenbo, W.; Enkuan, L.; Cundong, X. Assessment model of ecoenvironmental vulnerability based on improved entropy weight method. The Scientific World Journal 2014, 2014, 1-7.

[10]Deng, J. Control problems of grey system. Systems \& Control Letters, 1982, 1, 288-294.

[11]Erdal, K.; Baris, U.; Okyay, K. Grey system theorybased models in time series prediction. Expert Systems with Applications, 2010, 37, 1784-1789.

[12]Rapport, D.J. Luisa, M. Eco-cultural health, global health, and sustainability. Ecological Research, 2011, 26, 1039-1049.Luigi T.De Luca, Propulsion physics (EDP Sciences, Les Ulis, 2009) . 